\title{
SINDICALISMO E PRODUÇÃO FLEXÍVEL NO SETOR AUTOMOTIVO: COOPTAÇÃO E FRAGMENTAÇÃO INSTITUCIONAL NO SUL FLUMINENSE ${ }^{1}$
}

\author{
Pedro Luiz Maitan Filho \\ Ana Lucia Guedes ${ }^{3}$
}

http://dx.doi.org/10.1590/1413-2311.202.75917

\begin{abstract}
RESUMO
Os sindicatos dos trabalhadores do setor automotivo protagonizam, nas últimas décadas, discussões sobre a expansão do modelo de produção flexível e, concomitantemente, a ampliação de condições de trabalho desregulamentadas em subsidiárias de montadoras no sul fluminense. Pesquisas sobre a fragmentação institucional das centrais sindicais, a influência do lobby corporativo e a cooptação dos sindicalismos regionais em arranjos políticos, têm possibilitado um diálogo transversal entre pesquisadores de países anfitriões do regime automotivo da segunda metade do século XX. Delimitado a uma região distanciada dos maiores centros industriais brasileiros, o artigo tenciona aprofundar discussões sobre atuação dos sindicatos em regiões industrializadas a partir da redistribuição espacial das montadoras em território nacional. Os resultados produzidos por entrevistas com profissionais da subsidiária estão organizados em três subcategorias fundamentadas na revisão de literatura: (a) relação entre atuação sindical e recorte regional; (b) divergência de pautas entre sindicato metalúrgico e temas específicos da montadora, e (c) uso político do sindicato por meio de cooptação. Os resultados mostram, predominantemente, prejuízos para acordos coletivos e condições de trabalho; impressão de perfil profissional do sindicato desalinhado das demandas na subsidiária; e, desconfianças quanto a tratativas entre sindicato e empresa. Esses aspectos sugerem generalizações analíticas da pesquisa qualitativa no sul fluminense para
\end{abstract}

\footnotetext{
${ }^{1}$ Recebido em 24/08/2017, aprovado em 29/03/2018.

${ }^{2}$ Universidade do Grande Rio (Brasil) - maitan.pedro@gmail.com

${ }^{3}$ Fundação Getúlio Vargas (Brasil) - almguedes@gmail.com
} 
outras subsidiárias em greenfields automotivos; sobretudo na identificação de mecanismos que dispersam a representação institucional dos sindicatos na indústria automotiva.

Palavras-chave: Trabalho. Sindicato. Produção Flexível. Indústria Automotiva.

\title{
UNIONISM AND FLEXIBLE PRODUCTION IN THE AUTOMOTIVE SECTOR: COOPTATION AND INSTITUTIONAL FRAGMENTATION IN SOUTH- FLUMINENSE REGION
}

\begin{abstract}
Trade unions of automotive workers lead, in recent decades, discussions about the expansion of the flexible production model and, concomitantly, an enlargement of deregulated working conditions in subsidiaries of automakers in south-fluminense region. Research on the institutional fragmentation of trade union centrals, the influence of corporate lobbying, and the co-optation of regional syndicalism in political arrangements have enabled a transversal dialogue between researchers from different countries those who have hosted the automotive regime since the second half of the 20th century. Delimited to a region distant from the largest industrial centers in Brazil, the article intends to deepen discussions about the performance of trade unions in regions industrialized from the spatial redistribution of the automakers in national territory. The results produced by the interviews, with the professionals of the subsidiary, are organized in three subcategories based on the literature review: (a) relationship between union activity and the regional delimitation; (b) divergence of guidelines between the metallurgical union and specific issues of the automotive industry, and (c) political use of the union through co-optation. The results show, predominantly, damages to collective agreements and on working conditions; impression that the professional profile of the union is out of line with the demands of the subsidiary; and suspicions about the negotiations involving union and the company. These aspects suggest analytical generalizations of qualitative research in the south-fluminense region for other subsidiaries in automotive greenfields, especially in the identification of mechanisms that disperse the institutional representation of unions in the automotive industry.
\end{abstract}

Keywords: Labor. Labor Union. Flexible Production. Automotive Industry.

REAd | Porto Alegre - Vol. 24 - No 1 - Janeiro / Abril 2018 - p. 149-178 


\title{
SINDICALISMO Y PRODUCCIÓN FLEXIBLE EN EL SECTOR AUTOMOTOR: COOPTACIÓN Y FRAGMENTACIÓN INSTITUCIONAL EN EL SUR FLUMINENSE
}

\begin{abstract}
RESUMEN
Los sindicatos de los trabajadores del sector automotriz protagonizan en las últimas décadas discusiones sobre la expansión del modelo de producción flexible y, concomitantemente, la ampliación de condiciones de trabajo desregulamentadas en subsidiarias de montadoras en el sur fluminense. Las investigaciones sobre la fragmentación institucional de las centrales sindicales, la influencia del lobby corporativo y la cooptación de los sindicalismos regionales en arreglos políticos, han posibilitado un diálogo transversal entre investigadores de diferentes países anfitriones del régimen automovilístico iniciado en la segunda mitad del siglo XX. Delimitado a una región distanciada de los mayores centros industriales en Brasil, el artículo tiene intención de profundizar discusiones sobre actuación de los sindicatos en regiones industrializadas a partir de la redistribución espacial de las montadoras en territorio nacional. Los resultados producidos por entrevistas con profesionales de la subsidiaria están organizados en tres subcategorías, fundamentadas en la revisión de literatura: (a) relación entre la actuación sindical y el recorte regional; (b) divergencia de pautas entre el sindicato metalúrgico y temas específicos de la industria automotriz, y (c) uso político del sindicato por medio de cooptación. Los resultados muestran, predominantemente, perjuicios para acuerdos colectivos e en las condiciones de trabajo; impresión de perfil profesional del sindicato desalineado de las demandas en la subsidiaria; y, desconfianzas en cuanto a las tratativas que involucran sindicato y empresa. Estos aspectos sugieren generalizaciones analíticas de la investigación cualitativa en el sur fluminense para otras subsidiarias en greenfields automotores; Sobre todo en la identificación de mecanismos que dispersan la representación institucional de los sindicatos en la industria automotriz.
\end{abstract}

Palabras-clave: Trabajo. Sindicato. Producción Flexible. Industria Automotriz.

\section{INTRODUÇÃO}

Estudos sobre a baixa representação sindical na indústria têm se multiplicado na última década (KÖHLER, H; CALLEJA JIMÉNEZ, 2015). Dentre as diversas delimitações 
de análise desse fenômeno, uma se destaca em virtude do volume de contribuições teóricas recentes: a contraposição entre a atuação dos movimentos sindicais e a proliferação das estratégias de flexibilização laboral (PULIGNANO; GERVASI; FRANCESCHI, 2016; RAMALHO; RODRIGUES; CONCEIÇÃO, 2009). O que sublinha tal contraponto nos últimos anos é o fluxo de corporações para regiões que reúnem: mercado consumidor, baixos custos de produção, e ação sindical limitada (ABDI, 2011; ARAÚJO, 2012).

Nas montadoras, essa nova configuração industrial tem ensejado reflexões, apenas para citar, sobre o regionalismo sindical na China (LÜTHJE, 2014), o fracasso institucional dos sindicatos na África do Sul (BOLSMANN, 2012), e as modificações na legislação trabalhista que marginalizaram as mobilizações sindicais nos países do leste europeu (DRAHOKOUPIL; MYANT; DOMONKOS, 2015). Temáticas que ecoam em outros estudos nos países emergentes (GASTROW, 2012).

Pesquisas recentes no Brasil (RAMALHO; RODRIGUES, 2013), no contexto europeu (BENGTSSON, 2014) e norte-americano (MAGNANI; PRENTICE, 2010) mostram a relação inversa entre a densidade sindical e a flexibilidade no trabalho - bem como o aumento dos custos de produção. Isso sinaliza - e também justifica - a desconfiança de alguns pesquisadores quanto aos modelos triangulares formados por empresas, governos e sindicatos que viabilizam o lobbying das montadoras (ADAMS; DEAKIN, 2014), e a cooptação por partidos na tessitura política municipal ou estadual (DAL ROSSO, 2013).

Representações sindicais fragmentadas são abafadas, sobretudo em localidades distantes dos grandes centros industriais (TANIGUTI, 2009) em estruturas montadas para atração de investimentos (ARBIX, 2012) que promovem um sincretismo estranho e prejudicial entre empresas e sindicatos (SOARES, 2013). Sendo assim, análises sobre a atuação do sindicato no setor automotivo abordam tanto detalhes de micro abrangência, ou inscritos aos domínios municipais ou estaduais (ARAÚJO, 2012), quanto conjunturas maiores e determinadas pela produção flexível internacional (GARCIA, 2010; LIMA, 2015).

A inserção dos países ditos emergentes na global production network automotiva ocorre - dentre outras variações - mediante à confluência econômica, política e discursiva que coincide com a implantação de práticas laborais cada vez mais flexíveis (CANTIN, 2013; LEVY, 2008). Nessa lente de análises, sindicatos aparecem inoperantes diante da globalização do sistema de produção automotivo (WADDINGTON, 2015) e, consigo, a proliferação do part-time na Coreia do Sul (AELIM, 2011), das demissões em massa na Austrália (ANAF et al., 2012), ou das chantagens das empresas no Brasil com pretexto da maior escassez de vagas no setor automotivo (ANNER, 2014). 
Consequentemente, pesquisadores questionam o advento industrial deficitário em países anfitriões do regime automotivo desdobrado a partir da segunda metade do século XX (BARROS; PEDRO, 2011), e o protagonismo inverso dos sindicalismos regionais nas discussões sobre problemas de representação coletiva dos trabalhadores (WAD, 2005). Discussões, inclusive, mais centradas nas particularidades da relação matriz-subsidiária (CHUNG, 2015) em novas regiões produtivas denominadas de greenfields automotivos (LAWLER et al., 2013).

Este artigo reforça críticas à produção flexível na indústria automotiva global, realçando os sindicatos como locus da argumentação (PULIGNANO; LUCIO; WALKER, 2013). Delimitada geograficamente a uma região distanciada dos maiores centros industriais do Brasil - leiam-se os municípios de Santo André, São Bernardo e São Caetano, na região metropolitana de São Paulo capital; e região Sul do país (COELHO, 2012) - a pesquisa tenciona aprofundar as discussões teórico-empíricas sobre a atuação dos sindicatos em regiões industrializadas após a dispersão montadoras nas últimas décadas (ANFAVEA, 2016).

O processo demissional e de mudanças estruturais instalado na subsidiária investigada se agrava desde a retração econômica de 2008. Além das demissões em massa no nível operacional, também proliferou, nos períodos seguintes, a contratação de terceirizados e de subcontratados para áreas administrativas. A precarização identificada em diversos cargos funcionais sublinhou, assim, fragilidades da representação sindical e também a assimetria de poder nas negociações coletivas. Em contexto ampliado, a investigação de tal fenômeno possibilita traçar paralelos com outros estudos focados nas montadoras.

A pesquisa qualitativa foi realizada por meio de entrevistas longas com profissionais da área designada na subsidiária como Processos Industriais, responsável pelas mudanças estruturais. Os registros de gravação de voz foram autorizados pelos entrevistados por meio da assinatura de Termo de Consentimento que, juntamente com permissão para veicular o material coletado, também assegura na pesquisa a confidencialidade da fonte. Trechos literais das entrevistas foram organizados em subcategorias de análise.

As subcategorias estão fundamentadas na revisão de literatura e abordam: (a) a relação entre a atuação sindical e o recorte regional; (b) a divergência de pautas entre sindicato metalúrgico e temas da indústria automotiva, e (c) o uso político do sindicato por meio de cooptação. Os resultados mostram, predominantemente, prejuízos para os acordos coletivos e impactos nas condições de trabalho; a impressão de que o perfil profissional do 
sindicato está desalinhado das demandas na subsidiária; e, desconfianças quanto às tratativas que envolvem sindicato e empresa.

O artigo está estruturado em seis seções além desta breve introdução. Na segunda seção são apresentadas as discussões teóricas que situam os sindicatos dentro do contexto da flexibilização do trabalho industrial em nível global. Na terceira seção essa discussão é delimitada ao setor automotivo por meio de pesquisas teórico-empíricas em montadoras instaladas em países emergentes - por reproduzirem configurações semelhantes à região estudada. A seguir, os procedimentos metodológicos e, na quinta seção, as análises das subcategorias adotadas na investigação. Por fim, são concatenadas as conclusões sobre os resultados e apontados temas para futuras pesquisas.

\section{SINDICATO E SETOR AUTOMOTIVO: ENTRE A FLEXIBILIDADE E A FRAGMENTAÇÃO INSTITUCIONAL}

Dentre as preocupações dos pesquisadores do regime industrial automotivo nos países emergentes (LIMA, 2015; AUGUSTO JÚNIOR et al., 2015), tem especial destaque a dispersão de montadoras para regiões com características de trabalho atípicas (NEVES, 2011). Esse fenômeno coincide com os privilégios fiscais (BARROS; PEDRO, 2011), menores salários (FRANCO, 2009) e, especialmente, a menor intensidade nas pressões de sindicatos dos trabalhadores durante acordos coletivos (NASCIMENTO; SEGRE, 2008).

A revisão de literatura, organizada em duas partes, debate primeiramente estudos sobre a convergência entre o engessamento dos sindicatos e o maior alcance da flexibilidade no trabalho na indústria (MAGNANI; PRENTICE, 2010; BENGTSSON, 2014). Tendo esse direcionamento, a segunda parte localiza a discussão na indústria automotiva com a experiência dos pesquisadores em subsidiárias nos países emergentes. Esse percurso é intencional no sentido de possibilitar as generalizações analíticas do caso investigado no sulfluminense para outras regiões pesquisadas em contexto similar.

\subsection{OS SINDICATOS NO CONTEXTO DE FLEXIBILIDADE NO TRABALHO INDUSTRIAL}

$\mathrm{O}$ argumento mais importante dessa discussão reside sobre o fato de que o fenômeno da globalização, bem como o advento de novas tecnologias, têm sido vetores potenciais de nova configuração do trabalho industrial (SILVA, 2012). Assim, a palavra 
flexibilidade - apesar de empregada em literatura mainstream como um atributo de bom desempenho - tem denotado reestruturação produtiva e adequação de vínculos laborais numa balança que tende a privilegiar o capital, ao invés do trabalho (LÉVESQUE et al., 2015).

Conforme afirma Silva (2012, p.121), “[...] a predominância de novo perfil empresarial exigiu releituras dos sindicatos sobre o comportamento dos trabalhadores nessa fase do capitalismo global". Nesse contexto, é notável o número de pesquisadores que analisam um declínio nas mudanças de natureza reivindicatória que caracterizaram movimentos sindicais, e concomitantemente, a emergência das estratégias que visam o seu completo desmantelamento.

Estudos não somente advogam, como também propõem, novas estruturas nas relações entre empresas, sindicatos e governos sob os pretextos da necessidade de mobilizações sociais diferenciadas em ambientes complexos (ADAMS; DEAKIN, 2014). O pano de fundo de tais proposições tem despertado preocupações em relação aos desdobramentos no processo de fragmentação e a precarização do trabalho. Paralelamente, problemáticas importantes recaem justamente sobre a atuação sindical, uma vez que, notadamente, é reconhecida como a instância principal de interlocução entre trabalhadores e empresas.

As perguntas formuladas por Soares (2013) ecoam em outras pesquisas que estabelecem comparações entre diferentes fases históricas do sindicalismo - neste caso, no Brasil -, principalmente por considerar o surgimento de novos polos industriais que se instalaram fora dos grandes centros econômicos:

Indagações parecem pertinentes: o que leva as centrais sindicais a escolherem por uma política de parceria e aproximação com o governo, em detrimento de uma linha mais conflitiva? O fenômeno da aproximação das centrais sindicais seria responsável pela acomodação política na ofensiva das organizações no tocante à reestruturação produtiva, flexibilização e precarização do trabalho? Dito de outra maneira, as centrais sindicais não estariam operantes frente à ofensividade do capital sobre o trabalho? (SOARES, 2013, p.541).

O que causa estranhamento para Soares (2013) - além do sincretismo político de partes originalmente opostas - é o crescimento de estruturas ditas fantasmas, que resultaram, ambos: do intuito de confundir a representatividade da pauta trabalhista, e também da 
facilidade com que se registra um sindicato no Brasil. Ainda conforme detalha o autor, há situações em que se cria sindicato por meio de interlocutores completamente alheios à categoria a ser representada, e esta tem sido uma metodologia de classe cada vez mais usada justamente na fragmentação de forças.

Dessa questão, acabam derivando outras, não menos importantes, como a viabilização dos ditos programas de reengenharia fabril, os planos de jornadas atípicas de trabalho e reforço de competências rotuladas como multifuncionais - que normalmente impactam no contingente operacional (FLEIG et al., 2005). Assim, essa argumentação contempla as centrais sindicais com atrasos no tocante aos enfrentamentos gerados pelo pacote de flexibilidades estruturais, aplicadas sob o amparo da legislação trabalhista permissiva e que legitima tal cenário (SILVA, 2012).

Em contextos com maior interferência sindical, estudos apontam que a média salarial é maior, porém com aumento dos custos de produção (BENGTSSON, 2014). Não é por acaso a desconfiança em relação aos acordos entre empresas, sindicatos e governos em diversas instâncias administrativas (SOARES, 2013; SILVA, 2012). Com esse enfoque, Magnani e Prentice (2010) realizaram uma simulação estatística que já poderia servir de base para tais conjecturas. Os próprios autores já argumentavam que poucas pesquisas até então haviam buscado verificar (empiricamente) a aderência entre atuação sindical, custos de produção e flexibilidade organizacional.

Dentre os resultados encontrados, sobressaiu-se o seguinte: “[...] a variável flexibilidade oscila inversamente com a interferência do sindicato" (MAGNANI; PRENTICE, 2010, p.678). Cabe citar que o nível de sindicalização possui relação diretamente proporcional com o número de ganhos auferidos pelos trabalhadores. $\mathrm{O}$ trabalho destes pesquisadores abrangeu diversos setores industriais em recorte temporal de mais de duas décadas.

Outra pesquisa também apoiada em testes de hipóteses foi feita Bengtsson (2014). Neste caso, o objetivo foi avaliar como tem ocorrido a distribuição entre capital e trabalho no contexto da complexidade institucional das relações industriais. Os sindicatos aparecem como um elemento fundamental da estrutura corporativa que também envolve governos. $\mathrm{Na}$ hipótese referente especificamente à atuação sindical enquanto membro da estrutura institucional, Bengtsson (2014) constata a associação positiva entre a densidade sindical e a distribuição dos salários nos últimos 50 anos.

As diferenças de equidade na distribuição do capital, segundo o autor, relacionam-se ao modus operandi praticado por sindicatos em diferentes contextos. O estudo 
mostra que efeitos da atuação sindical na Europa continental são mais contundentes que nos países nórdicos, por exemplo. Essa questão é central para responder problemas identificados no sul fluminense e outras regiões que, como apontam pesquisadores, não contam com pressões que tradicionalmente deveriam emanar do sindicato regional.

Assim, como no contexto norte-americano (MAGNANI; PRENTICE, 2010) e europeu (BENGTSSON, 2014), a questão da densidade institucional dos sindicatos também tem mobilizado pesquisas no Brasil. Informações compiladas por Dal Rosso (2013), de 2001 a 2012, mostram crescimento de quase $10 \%$ no número de sindicatos no Ministério do Trabalho e Emprego, o que suscitou questionamento do porquê da ampliação do número de sindicatos; além da suspeição de que as novas bases sindicais podem representar, na essência, apenas a fragmentação de representação:

No processo fragmentação [...] Centrais sindicais podem ocupar espaço para um ou mais partidos políticos [...] Raras são as centrais, hoje, se há por acaso alguma, que não se vincula a um partido [...] $\mathrm{O}$ sindicato fragmenta-se. Essa função é própria do sindicalismo não apenas no Brasil, como também nos demais países do mundo. Raramente é capaz de unificar trabalhadores, e frequentemente os divide (DAL ROSSO, 2013, p.51).

Sendo assim, surge uma inflexão nas discussões sobre a atuação sindical: se de um lado, existe uma correlação direta entre sindicalismo e ganhos da causa trabalhista (ADAMS e DEAKIN, 2014; BENGTSSON, 2014; MAGNANI e PRENTICE, 2010), em sentido oposto, também estão em curso estratégias em nível global para desmantelar iniciativas unificadoras e viabilizar modelos de produção cada vez mais flexíveis (DAL ROSSO, 2013; ANNER, 2014). Por esse viés, pesquisas sublinham assuntos como corrupção e desregulamentação (KÖHLER e CALLEJA JIMÉNEZ, 2015) em vínculos que unem o poder público, os sindicatos e as empresas (ARAÚJO, 2012).

No sul fluminense, a confluência dos interesses locais na conformação do trabalho são temas relevantes, na dimensão microestrutural, no tocante aos impactos que têm inibido a representação sindical genuína (LIMA, 2006; RAMALHO e SANTANA, 2006). No contexto internacional, concomitantemente, a consolidação de um modelo de produção flexível descortina imposições do capital com efeitos semelhantes em países emergentes (GASTROW, 2012; LIMA, 2015). 
$\mathrm{Na}$ próxima seção, a discussão será delimitada ao setor automotivo. Tradicionalmente marcadas por mobilizações sindicais (RAMALHO; RODRIGUES, 2010), coube antes demarcar problemáticas nas montadoras referentes aos interesses entre diferentes atores que tem interfaces com sindicatos; bem como o processo de fragmentação institucional. Temas debatidos no horizonte da dispersão das montadoras no Brasil para novas regiões produtivas (COELHO, 2012; BARROS; PEDRO, 2011).

Em anos recentes, o Brasil disputa com concorrentes estrangeiros pelos investimentos externos das montadoras, dado o advento industrial indiano, coreano, chinês e de países do leste europeu (ABDI, 2011). Os sindicatos aparecem destacados nesses países pelos mesmos motivos que marcam baixa institucionalidade e produção flexível (ZHU, 2015; CHUNG, 2015). Assim, as características do trabalho nos greenfields (LAWLER et al., 2013) têm sido um instigante objeto de análise, sobretudo na relação entre empresas e sindicatos.

\subsection{DISCUSSÕES CONTEMPORÂNEAS SOBRE O SINDICALISMO NO SETOR AUTOMOTIVO}

A premissa de Lüthje (2014), no estudo com montadoras chinesas, é de que as relações de trabalho na indústria vêm se tornando mais instáveis. O pesquisador adverte para a ausência de sindicatos independentes em algumas regiões, como também a inexistência de acordos coletivos formais. Um tópico da pesquisa na China que se sobressai entre os demais é a comparação entre eventos do chão-de-fábrica e da sociedade.

Diversas pesquisas no Brasil seguem a linha de Lüthje (2014), ao situar sindicatos das novas regiões produtivas como extensões da própria mobilização social que tende a ser menos contundente do que em lugares de tradição industrial. No modelo institucional de trabalho suportado exclusivamente pelas diretrizes do Partido Comunista, Lüthje (2014) defende a criação de agendas específicas em prol dos trabalhadores. Nesse sentido:

[...] as greves mostraram divisões entre forças de trabalho centrais e outras extremamente flexíveis, com trabalhadores de baixos salários e nos níveis intermediários e inferiores das pirâmides, como fornecedores. Movimentos semelhantes não ocorreram nessas outras regiões, em parte por causa de propriedade, dos modelos de produção e das forças de trabalho que são estruturadas de forma diferente em 
outras áreas de fabricação de automóveis na China (LÜTHJE, 2014, p.556).

$\mathrm{Na}$ indústria automobilística sul-africana, Bolsmann (2010) também traça um paralelo, porém não levando em conta a questão regional, e sim o grau de internacionalização dos sistemas de produção. O autor denomina de velha e nova as duas formas de trabalho, e, assim como Lüthje (2014), também observa um maior engessamento do sindicalismo no segundo momento. O recorte da análise se dá no ano 2000, quando montadoras do país ingressaram gradativamente na rede de produção global automotiva.

Concomitantemente, pressões confrontaram os sindicatos na África do Sul, sobretudo devido a demissões em massa e uma série de reconfigurações laborais no remanescente que continuou com contratos ativos. Negociações ineficazes e assimétricas mostraram o total insucesso institucional dos sindicatos que não contestaram veementemente diante do corte de mais de mil postos de trabalho na indústria automotiva. É importante reiterar que o ponto crítico da pesquisa de Bolsmann (2010) trata do processo de flexibilidade industrial, sobre o qual sindicalistas não tiveram reação à altura.

No contexto sul-coreano, Aelim (2011) descreve condições informais de trabalho e lista vínculos que se proliferaram no setor automotivo: part-time, subcontratados e jornadas diferenciadas. Como Bolsmann (2010), o pesquisador enfatizou a busca por redução de custos que gerou maior flexibilidade na gestão da produção e das práticas de emprego. Condições de trabalho mais precarizadas são analisadas a luz de processos globais, e os sindicatos são apontados, sobretudo a partir de 2003, como impotentes na articulação coletiva.

O mote de Aelim (2011), na Coreia do Sul, é questionar a exclusão de terceirizados e/ou temporários nos mesmos acordos dos trabalhadores regulares. Outra pesquisa no mesmo contexto, de Waddington (2015, p.1), pergunta: “[...] Foi, porventura, o sindicato das montadoras condicionado pelo processo de globalização da indústria local?”. A resposta proposta pelo próprio autor é um sim contextualizado. Novamente, fica em destaque a preocupação com a dissolvência de ações sindicais coordenadas, e como a implantação da flexibilidade laboral tem sido tema central nesse processo.

No contexto brasileiro, destaca-se a pesquisa intersetorial de Anner (2014), que aborda políticas intersindicais em nível internacional. $\mathrm{O}$ autor concluiu que, dentre as indústrias investigadas, a automotiva tem sido a mais vulnerável aos interesses do capital externo. A questão da regionalização industrial para municípios com menor densidade 
sindical foi mencionada como estratégia das corporações pautada no market seeking sobretudo nas décadas de 1950 e 1960.

Entretanto, um adicional importante é colocado por Anner (2014, p.233), ao comentar o que chama de chantagens feitas por montadoras aos sindicatos usando como pretexto a reconfiguração da concorrência no Brasil e a divisão do mercado entre novos entrantes: “[...] os gerentes de empresas sindicalizadas colocaram representantes dos trabalhadores uns contra os outros, mencionando pressões dos concorrentes de baixo custo". Trata-se de um problema identificado em montadoras mais antigas no país - foram citadas Ford, GM e Volkswagen -, e indica como a escassez de postos de trabalho tem sido articulada como um tema que fragmenta, ao invés de fortalecer, a agenda dos sindicatos.

As demissões em massa na indústria automotiva australiana foram estudadas por Anaf et al. (2012, p.329) à luz de uma configuração institucional que envolveu, dentre outros: “[...] mudanças legislativas que marginalizaram o papel e o poder dos sindicatos frente a negociações coletivas". Os autores coletaram dados nos anos de 2005-2007 por meio de entrevistas com pessoas atingidas pelas demissões iniciadas no país em 2004. Quanto a questões que caberiam ao sindicalismo, as análises pautaram termos como cerceamento, restrições e declínio do Sindicato dos Trabalhadores da Indústria Australiana (AMWU):

Diversos trabalhadores explicaram que, ainda que o sindicato pudesse ajudar, suas 'mãos estavam amarradas' [...] A restrição do sindicato foi um tema comum na pesquisa, com os trabalhadores dizendo que parecia não haver coisa a ser feita por eles, ou ainda afirmando que: no mercado global não há muitas garantias (ANAF et al., 2012, p.333).

A pesquisa de Drahokoupil, Myant e Domonkos (2015, p. 223) investigou subsidiárias automotivas na República Tcheca, Eslováquia e Hungria, onde: “[...] a flexibilidade dos empregos se tornou uma importante questão, e uma arena de conflitos com sindicatos". Os autores ainda complementam dizendo que essas são áreas institucionalmente fracas em relações industriais e, sendo assim, o trabalho tem sido condicionado por fatores de mercado e conveniências das matrizes.

Assim como no caso da Austrália, a exacerbação de mudanças na legislação trabalhista - sobretudo na República Tcheca e Eslováquia - culminou na desagregação, a partir dos anos 1990, de centrais sindicais em organizações locais com poderes 
descentralizados. Os autores admitem que, em comum, a instalação de subsidiárias representou uma fuga de regulamentações estritas nos países de origem. Esse tem sido o elo entre estudos nos países emergentes, onde a produção automotiva se caracteriza pela flexibilidade e por novos enfrentamentos dos sindicatos; conforme a síntese apresentada no Quadro 1.

\section{Quadro 1 - Síntese das discussões teóricas focadas na atuação sindical}

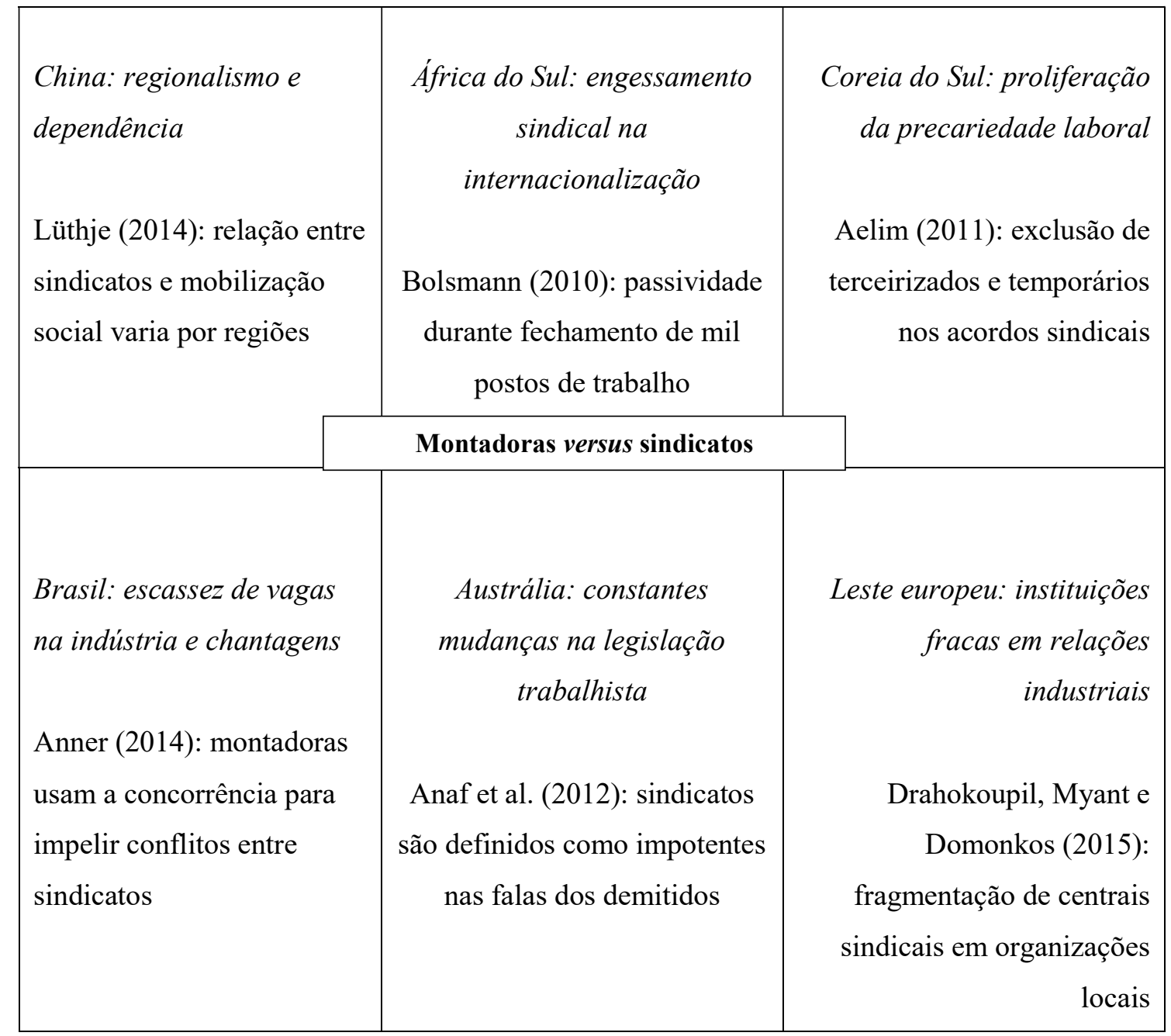

Fonte: elaborado pelos autores.

Centrada, ambos, no setor automotivo e em países emergentes (GASTROW, 2012), a revisão de literatura aborda mecanismos adotados pelas montadoras para desestabilizar arranjos políticos locais e legitimar institucionalidades para a nova fase de dispersão da indústria (ARAÚJO, 2012). Outros estudos em regiões do market seeking automotivo, como de Kuboniwa (2009) na Rússia, Wad (2005) na Malásia, e Chung (2015) na Índia, repercutem diferentes nuances a flexibilidade e os impactos para os sindicatos. 
Trata-se, portanto, de fenômenos reproduzidos em diferentes contextos e que, nessa investigação, são basilares para análises dos resultados encontrados no sul fluminense.

\section{PROCEDIMENTOS METODOLÓGICOS}

A pesquisa empírica e qualitativa (STAKE, 2010), que origina este artigo, foi realizada em subsidiária automotiva que iniciou suas operações no país no início dos anos 2000 (INSTITUCIONAL, 2016). A delimitação da pesquisa tem um recorte temporal a partir das primeiras reestruturações em 2008, quando na montadora começou um importante ciclo de demissões e, concomitantemente, mudanças na área dos Processos Industriais: antes funcional, passou para a estrutura matricial com equipes temporárias, e de apenas dois anos de contrato.

Três temas se destacam no estudo original: as transformações nas relações estabelecidas entre trabalhadores e representantes sindicais; os fluxos de trabalho com as hierarquias da então nova estrutura matricial; e os processos junto a fornecedores locais e externos. Do resultado produzido nas entrevistas longas (McCRACKEN, 1988) com profissionais lotados na área de Processos Industriais, foi possível anotar o volume de comentários e a contundência das afirmações sobre o sindicato regional. Fato coincidente com relato de pesquisadores de outras montadoras nos países emergentes - já alertado na revisão de literatura.

Assim, os resultados analisados referem-se, exclusivamente, às respostas sobre atuação do sindicato regional mediante transformações no trabalho, decorrentes do processo de reestruturação na subsidiária. As entrevistas foram agendadas, registradas por meio de gravação de voz e submetidas ao termo de consentimento para a veiculação do conteúdo (ROESCH; FERNANDES, 2007). O Quadro 2 apresenta síntese do perfil profissional dos entrevistados.

A seleção de sujeitos segue a recomendação de Duarte (2002) quanto às garantias de se assegurar coerência entre objetivos e coleta de dados. Os entrevistados estão lotados em cargos funcionais diretamente relacionados ao processo de produção, e portanto tiveram interfaces: com o desmonte do contingente da montadora pelo fechamento de turnos; com a implantação de tecnologias que flexibilizaram o trabalho e, principalmente, com representantes sindicais nos períodos dos acordos coletivos. 


\section{Quadro 2- Perfil profissional dos entrevistados}

\begin{tabular}{|c|c|c|c|c|}
\hline CÓD. & GÊNERO & GRADUAÇÃO & CARGO & ÁREA \\
\hline E-1 & Masculino & $\begin{array}{c}\text { Mestrado } \\
\text { incompleto }\end{array}$ & Engenheiro de Processo & Processo industrial \\
\hline E-2 & Masculino & $\begin{array}{c}\text { Mestrado } \\
\text { incompleto }\end{array}$ & Analista de Processo & Processo industrial \\
\hline E-3 & Masculino & $\begin{array}{c}\text { Mestrado } \\
\text { incompleto }\end{array}$ & Analista de Processo & Processo industrial \\
\hline E-4 & Masculino & Graduado & Engenheiro de Processo & Processo industrial \\
\hline E-5 & Masculino & Pós-graduado & Analista de Processo & Processo industrial \\
\hline E-6 & Masculino & Graduado & Analista de Projeto & $\begin{array}{c}\text { Processo industrial } \\
\text { (Projetos) }\end{array}$ \\
\hline E-7 & Masculino & Pós-graduado & Engenheiro de Processo & Processo industrial \\
\hline E-8 & Masculino & Graduado & Engenheiro de Processo & Processo industrial \\
\hline E-9 & Masculino & Graduado & Supervisor de Processo & Processo industrial \\
\hline E-10 & Masculino & Pós-graduado & Engenheiro de Processo & Processo industrial \\
\hline E-11 & Feminino & Pós-graduada & Engenheira de Processo & $\begin{array}{c}\text { Processo industrial } \\
\text { (Qualidade) }\end{array}$ \\
\hline E-12 & Feminino & $\begin{array}{c}\text { Mestrado } \\
\text { Incompleto }\end{array}$ & Engenheira de Processo & Processo industrial \\
\hline
\end{tabular}

Fonte: elaborado pelos autores.

As entrevistas foram realizadas a partir de um roteiro definido por Vergara (2009) como semiaberto, uma vez que, ainda que fosse focalizado no assunto sindicato e previamente informado pela revisão de literatura, também abre espaços para explicações e relatos de experiências dos entrevistados. As análises pressupõem que o sindicato é uma categoria tratada a priori como explicativa do fenômeno no sul fluminense; logo, respaldada pela organização do arcabouço teórico que fundamenta a coleta de dados (BARDIN, 2011).

Desde as primeiras décadas do século XX, a análise de conteúdo tem se destacado pela quantidade de aplicações em estudos qualitativos e quantitativos (DESLANDES, 1994; GOMES, 2009). Nos estudos quantitativos discutem-se o uso de softwares, os critérios de contagem e a lógica na alocação de categorias (CASTRO; SARRIERA, 2011; SIMMONS et al., 2011). Nas pesquisas qualitativas, o cerne permanece na identificação crível de características do conteúdo da mensagem, e sua decomposição nas unidades de análise que geram categorias analíticas (BERG, 2001; ROESCH, 2009).

Para sistematizar 'sindicato' como categoria de análise do fenômeno no sul fluminense, o estudo adota procedimentos de Franco (2005). Assim, a partir das transcrições 
foram elaboradas unidades de contexto e de registro. A primeira resulta dos debates teóricos e justifica a inclusão do sindicato no roteiro de entrevistas. A segunda materializa recortes textuais das afirmativas e/ou explicações dos respondentes especificamente nesse tema. $\mathrm{Na}$ pesquisa original, procedimentos similares foram aplicados às demais categorias.

Adicionalmente, em coerência com o roteiro semiaberto, foi realizada a qualificação da categoria por meio de subcategorias específicas do estudo. As subcategorias compõem o que Vergara (2005) define como grade de análise mista: resultante de uma categoria tida como a priori por ter fundamentação no estado da arte, mas que não prescinde de dados originais emergentes nos relatos. Os resultados de tais subcategorias foram organizados a seguir por similaridade de respostas obtidas nas entrevistas.

\section{RESULTADOS E DISCUSSÃO}

A análise dos resultados está dividida em três subcategorias fundamentadas na revisão de literatura e interligadas tematicamente: (a) a relação entre atuação sindical e o recorte regional; (b) a divergência de pautas do sindicato metalúrgico e os temas específicos da indústria automotiva, e (c) o uso político do sindicato por meio de cooptação (conforme ilustra a Figura 1). A contundência das palavras usadas pelos entrevistados ao tratarem dos temas e as semelhanças entre as opiniões chamaram a atenção - ressalvando que as entrevistas ocorreram em diferentes datas e que seguiram regras de confidencialidade.

Figura 1 - Relação temática das subcategorias de análise

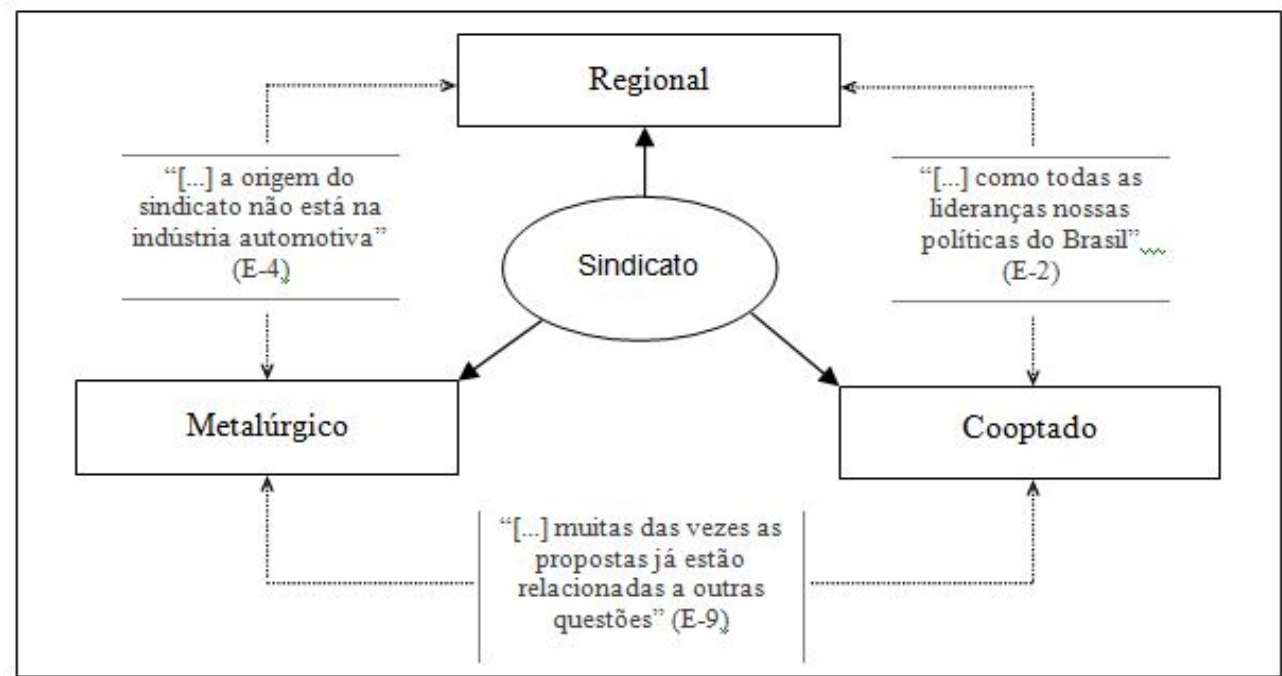

Fonte: elaborado pelos autores. 
Esse detalhe da pesquisa se assemelha ao fenômeno identificado por Anaf et al. (2012), em entrevistas com trabalhadores de montadoras na Austrália. Esses autores destacaram a quantidade de comentários sobre a fragilidade e o declínio dos sindicalistas diante das demissões em massa, o que mostra que eventos similares se reproduzem em diferentes localidades com subsidiárias automotivas.

De antemão, caberia contextualizar os fatores que acarretaram as novas pressões sobre o sindicato. Além da crise econômica desde meados de 2008 (BARROS; PEDRO, 2011), os respondentes descreveram a implantação de configurações laborais de curto prazo contratação de consultorias ou terceirizados - para composição de equipes com duração de dois anos. Essa condição foi relatada pelo Entrevistado 3: "Nós éramos contratados temporariamente no periodo de um ano, podendo ser prolongado por mais um ano".

Soma-se ao elemento contratos temporários, a recondução de tecnologias que reduziram o número de trabalhadores. Demissões, tanto em nível operacional como administrativo, se intensificaram, respectivamente, com a implantação de robôs enviados pela matriz e a fragilização dos vínculos laborais que são encerrados a cada dois anos. Tanto pressões no chão-de-fábrica (LÜTHJE, 2014), quanto reestruturações na gestão operacional são enfrentamentos ao sindicato no sul fluminense.

Outra questão que aparece neste estudo, porém já pautada em diversas pesquisas sobre a atuação sindical na indústria automotiva, é o impacto da regionalização na deterioração dos vínculos de trabalho (GARCIA, 2010; FRANCO, 2009). Na revisão de literatura, Magnani e Prentice (2010) e Bengtsson (2014) abordaram essa influência da densidade sindical sobre as condições de trabalho, e este mesmo aspecto apareceu nas entrevistas com trabalhadores no sul fluminense.

O recorte geográfico representa, assim, subcategoria relevante na análise do sindicato, tendo em vista as implicações regionais para conformação de institucionalidades que se conjuminam nas relações entre governos locais e empresas. Para ilustrar tal argumento, são apresentados a seguir alguns trechos de entrevistas que mostram como esse aspecto repercute entre os trabalhadores da subsidiária da montadora:

A gente conhece ai historicamente que ele [sindicato] tem uma atuação bem forte em outros centros produtivos mais antigos, como região do $A B C$ e até mesmo no sul do país, onde tem um pouco mais de tempo que tem algumas montadoras, né... O sindicato tem uma atuação bem forte, inclusive com participação de representantes da própria empresa (Entrevistado 5). 
[...] nessa região, ele [o sindicato] fica muito limitado [...] Eu observei que na sua pergunta você disse região, né?... Então, é isso mesmo! Tem tudo a ver com essa questão local (Entrevistado 9).

A questão do regionalismo foi discutida por Lüthje (2014) quando abordou a diferença, no contexto chinês, entre as mobilizações (leiam-se greves) articuladas nos centros de maior tradição industrial em relação a outras localidades com industrialização recente. Isso encaminha a primeira dimensão analítica do sindicato, referente à passividade e/ou omissão dos líderes sindicais. Surgiram, nessa dimensão, afirmativas categóricas como do Entrevistado 1: "Nunca vi o sindicato atuante na empresa". Importante ressaltar que foi detalhado ritmos caóticos na linha de montagem em função de variações horárias na produção.

As demissões são acompanhadas de incertezas: "Então é soma disso tudo né... São esses diversos fatores que acabam tornando a situação desfavorável pra gente" (Entrevistado 2). Subjetividades resultantes do cenário de maior insegurança foram consideradas por Silva (2012) ao analisar desafios para centrais sindicais diante da desregulamentação do trabalho. Sobretudo, quando usa comportamento como um termo para descrever reações dos trabalhadores em relação às novas delineações institucionais entre capital e trabalho.

Diante das sucessivas perdas com fechamento de postos de trabalho e reajustes médios de salários menores que em outros centros industriais, a associação com a inoperância do sindicato foi recorrente: "Eu acho o sindicato, em determinadas situações, bastante passivo" (Entrevistado 9). Ou ainda como opina o Entrevistado 4, especificamente sobre os acordos coletivos: “[...] funcionários sentem na pele, se sentem acuados porque ainda não conseguem ter reivindicações respeitadas". Relatos no sul fluminense repercutem os mesmos sintomas de impotência que Anaf et al. (2012) identificam na Austrália.

Dois eventos que se aproximam da pesquisa de Bolsmann (2010) na África do Sul são, primeiro, a inserção da subsidiária brasileira nos planos de modernização da matriz, e, segundo, demissões em massa derivadas de tal estratégia. Sobre a situação do sindicato, inclusive nos últimos problemas decorrentes dos efeitos da recessão econômica, o tom das respostas segue a análise do Entrevistado 2: "A gente tem um problema sério com o sindicato aqui né!". Tal comentário denota a ausência de expectativas no trabalho.

Tanto no contexto brasileiro como sul-coreano, pesquisadores advertem para o fracasso institucional do sindicato nas tessituras políticas locais em que montadoras e 
governos conformam modelos de trabalho flexíveis (BOLSMANN, 2010; ARAÙJO, 2012; DAL ROSSO, 2013). Assim, a impressão causada nos trabalhadores é a de que negociações coletivas não produzem melhores condições de trabalho. Além de institucional, relatos descrevem postura de certa passividade do sindicato nesses períodos:

Eu não via a atuação do sindicato fora dos periodos de acordo coletivo. Eles apareciam apenas no fim de ano ou nas horas em que tinha que combinar os valores, nada além disso (Entrevistado 10).

A segunda subcategoria de análise do sindicato regional no sul fluminense é a posição cética dos sujeitos em relação ao preparo de seus representantes em lidar com situações específicas da indústria automotiva. Assim, para os trabalhadores a imagem do sindicato está fortemente vinculada à siderurgia. Como registrou o Entrevistado 4: "[...] $a$ origem do sindicato não está na indústria automotiva, ele é do setor siderúrgico". Pesquisadores têm destacado o papel da Companhia Siderúrgica Nacional (CSN), em Volta Redonda, como um diferencial importante da região (ALVAREZ, 2004; PAULA, 2015).

Porém, na série de entrevistas, o vínculo de origem com outro setor de atividade enseja comentários sobre a desconexão entre sindicato e a pauta das montadoras. Tal condição também realça a análise de Soares (2013) sobre interlocuções inapropriadas quando da fundação das novas bases sindicais no Brasil. Ampliando para outros contextos onde as montadoras se instalaram nas últimas décadas, essa condição do sindicato tem paralelo com a fragmentação institucional no leste europeu, relatada por Drahokoupil, Myant e Domonkos (2015).

O Entrevistado 11 reforça a questão da origem do sindicato: “[...] O sindicato da região nasceu focado na indústria metalúrgica. Então ele não é voltado para área automotiva". Os problemas da produção flexível e o risco de demissões passam, aos entrevistados, a impressão de que montadoras ocupam um papel secundário na pauta mais imediata do sindicato - não obstante ser uma multinacional de grande porte. Essa condição pôde ser identifica em outros relatos:

O sindicato metalúrgico né... Ele representa mais o perfil deles. A gente tem um perfil bem diferente, que é o perfil automobilístico e tal. E os interesses nem sempre são iguais... Além disso, eu acho que deveria haver um sindicato específico pro setor automobilístico (Entrevistado 2). 
Há um pouco de descaso do sindicato com a empresa citada (Entrevistado 4).

O distanciamento entre trabalhador e sindicato acaba abrindo espaços para a persuasão e imposição do discurso gerencial. Como Anner (2014) comenta em pesquisa com outras montadoras no Brasil, o quadro de escassez de novas vagas possibilita o surgimento de um ambiente propício a chantagens por parte dos empregadores. O Entrevistado 9 fala a respeito ao reproduzir conversas no setor de Processos Industriais. Situação de mercado e de crise são argumentos usados para inibir eventuais reivindicações:

São várias as condições impostas, né... Porque eles dizem: "Há a condição de crise; há a condição de mercado ruim" etecetera... E infelizmente ficamos à mercê dessa situação (Entrevistado 9).

Ainda de acordo com a mesma entrevista, líderes sindicais endossam e disseminam essa mesma mensagem visando em, alguns casos, agilizar os acordos coletivos. Sendo ainda incisivo sobre a relação entre montadora e sindicato, o Entrevistado 7 sugere a ausência de isonomia entre líderes sindicais, e a isso denomina conchavo ou favorecimento: "[...] eu acredito que deve haver conchavo com o sindicato para algum tipo de favorecimento, entendeu?". Nessa fase das entrevistas nuances de cooptação começam a surgir.

O sincretismo entre sindicato e política foi discutido por pesquisadores como Dal Rosso (2013) e Soares (2013). Os relatos nas entrevistas indicam os prejuízos causados pela impressão de haver sindicato cooptado no sul fluminense. Isso também foi colocado, de forma sutil, por outro respondente, com base em observações nos acordos coletivos. O fornecimento de café e mesa para o sindicato é tratado com ironia porque denota postura comprometedora:

Alguns anos a gente vê até mesas da empresa, café fornecido pela empresa para o sindicato... Ou seja, até a relação entre o sindicato e a empresa tem uma certa oscilação, entende? [risos] $E$ a gente sempre vê o sindicato apenas nessas épocas [de acordos coletivos] (Entrevistado 8).

O uso político do sindicato foi bastante cogitado, e a profusão de comentário nesse tema alicerça a terceira subcategoria de análise designada como cooptação. $\mathrm{O}$ Entrevistado 2 faz uma análise ampliada de contexto: “Como todas as lideranças políticas do Brasil, o sindicato também é corrupto, né”. A mesma palavra foi usada pelo Entrevistado 7: “O sindicato não tem trabalho nenhum [risos] É muito corrupto". Na revisão de literatura, os 
esquemas triangulares envolvendo empresas, governos locais e sindicatos redundam na análise da prática de lobbying (ADAMS; DEAKIN, 2014).

A Figura 2 apresenta uma adaptação do esquema triangular usado por pesquisadores como Grosse e Behrman (1992) e Stopford (2005), com a alteração no vértice em que, originalmente, aparece a dimensão comunidade - neste caso, ocupada pelo sindicato. O mote da ilustração é demonstrar relações de barganha tanto na aresta sindicato-governo, quanto na aresta sindicato-empresa. Em cada aresta são posicionados trechos dos relatos que consubstanciam a recondução do triângulo para o tema em questão.

Figura 2 - Esquema triangular governo-empresa-sindicato

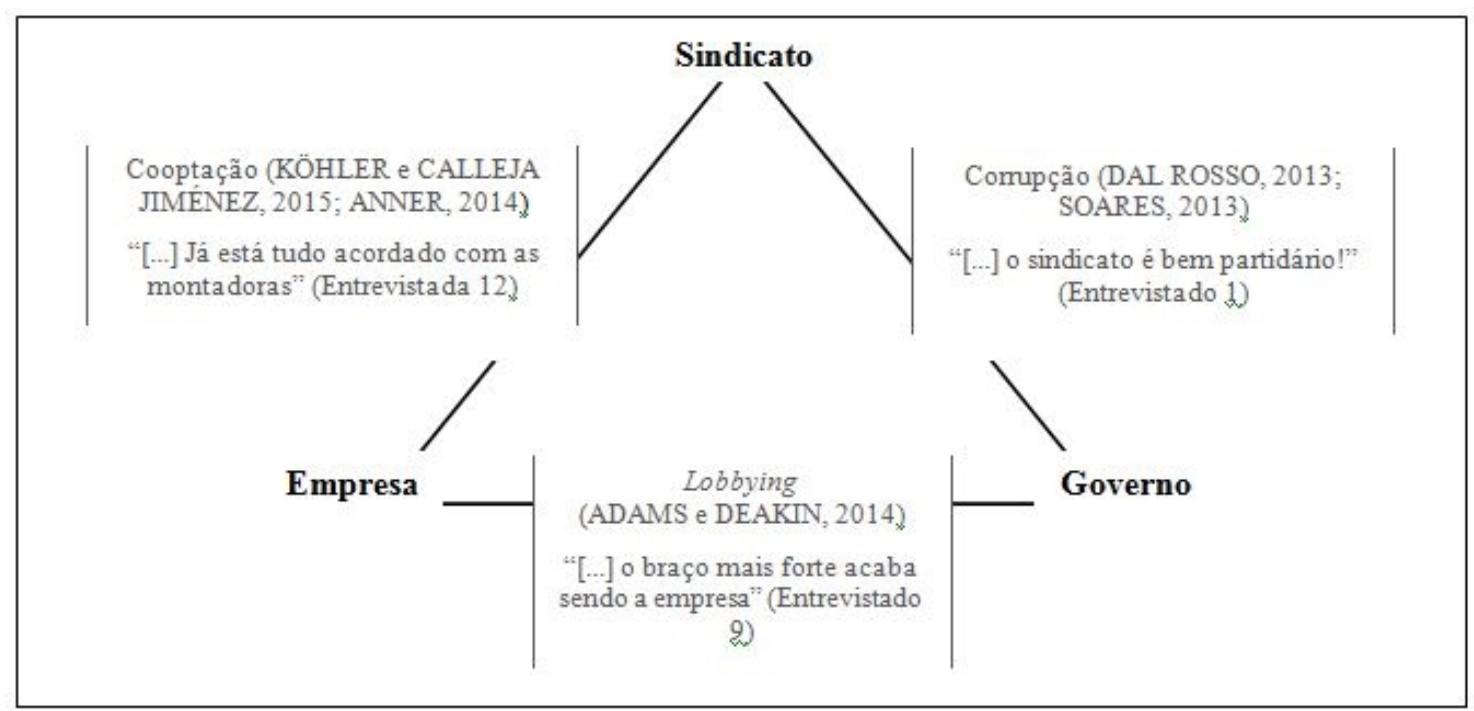

Fonte: adaptado de Grosse e Behrman (1992) e Stopford (2005).

Pesquisas recentes sobre a indústria automotiva brasileira (LIMA, 2016; LIMA, 2015; AUGUSTO JUNIOR et al., 2015) abordam a fase de dispersão do tecido industrial em território nacional. Regiões outrora inexpressivas no contexto da indústria recebem, no terceiro regime automotivo, um número proporcional maior de subsidiárias que centros tradicionais - ressaltam-se as regiões Norte e Nordeste (ANFAVEA, 2016). A inserção e destaque da região sul fluminense também constam desse fenômeno (LIMA, 2006).

Ainda que a interiorização da indústria seja discutida pela via da difusão tecnológica e a oferta massiva de empregos (RAIS/MTE, 2014), outra inquietação surge em relação ao momento atual de ociosidade da capacidade instalada (AUGUSTO JUNIOR et al., 2015). Tal cenário tem sido articulado discursivamente como agenda de política setorial com 
o objetivo de reduzir custos por meio de flexibilização de jornadas ou contratos curtos que desonerem obrigações das multinacionais nos países emergentes (DELGADO, 2015).

O modelo triangular resultante de barganha entre governo, empresa e sindicato é, assim, uma subcategoria importante quanto à conformação do trabalho regional. Pesquisas com foco na guerra fiscal por investimentos externos (ARBIX, 2002) detalham como estados e municípios acomodam políticas fiscais segundo conveniências do capital migrante das montadoras (ARAÚJO, 2012). Especificamente para o sindicato, novos enfrentamentos resultam dos arranjos de trabalho complexos e fragmentados (FRANCISCO, 2006).

A etapa recente do market seeking automotivo internacional afeta condições de trabalho em dimensões operacionais, sociais e discursivas (LEVY, 2008; DICKEN, 2011). Nas subcategorias selecionadas para a análise do sindicato, os temas destacados na pesquisa de campo foram: o recorte geográfico, o despreparo dos líderes sindicais e a cooptação política na tessitura política local. A Figura 3 sintetiza esses aspectos com base nas falas dos sujeitos da pesquisa.

Figura 3 - Síntese das falas dos sujeitos da pesquisa

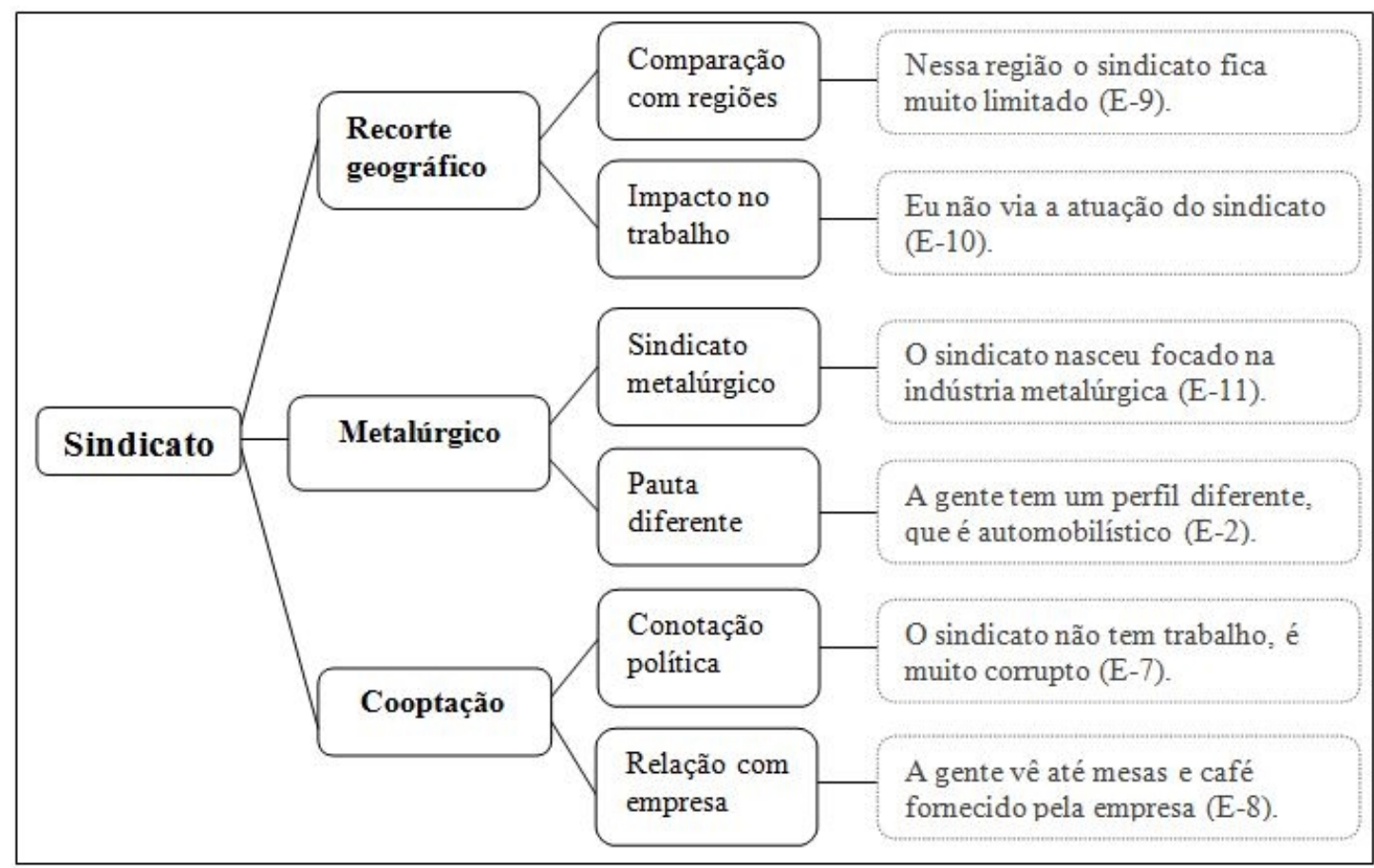

Fonte: elaborada pelos autores.

Eventos decorrentes da produção flexível em subsidiárias automotivas foram analisados em Juiz de Fora (NEVES; CARVALHO NETO, 2007), Camaçari (FRANCO, 
2009), Indaiatuba (TANIGUTI, 2010) e na região metropolitana de Curitiba (BRIDI, 2007). A preocupação em comum é a relocalização da indústria e consequências nas condições de trabalho. O sindicato, nessas pesquisas, constitui importante eixo analítico na escolha locacional das montadoras e, nesse sentido, torna-se fundamental na problematização da redistribuição espacial da indústria automotiva brasileira.

\section{CONSIDERAÇÕES FINAIS}

A pesquisa no sul fluminense fortalece discussões sobre a flexibilidade no trabalho, que caracteriza a redistribuição espacial das montadoras. A problematização da relação entre flexibilidade e atuação sindical e, posteriormente, os casos empíricos em diversos países emergentes, justificam a importância de sindicatos regionais como dimensão estratégica na lógica do novo tecido industrial automotivo nacional.

Adotado como categoria a priori no fenômeno de reestruturação produtiva na subsidiária de montadora no sul fluminense, o sindicato aparece com proeminência nas entrevistas com profissionais da área de Processos Industriais. Tais relatos foram divididos em três subcategorias temáticas: (a) a relação entre a atuação sindical e o recorte regional; (b) a divergência de pautas do sindicato metalúrgico e temas da indústria automotiva; e (c) o uso político do sindicato por meio de cooptação.

Em relação ao recorte geográfico no sul fluminense, as respostas cogitam passividade e a inexistência de pressões que tradicionalmente emanariam dos sindicatos. Essa questão foi abordada nas entrevistas por comparações com $\mathrm{ABC}$ e região sul do país. Igualmente sinaliza semelhanças com relatos dos trabalhadores chineses, que também comentaram sobre diferenças nas mobilizações, dependendo da região na China (LÜTHJE, 2014). A inoperância do sindicato também tem paralelo com o ocorrido na Austrália, diante das demissões em massa nas montadoras em meados dos anos 2000 (ANAF et al., 2012).

No sul fluminense, demandas para o sindicato resultam de reestruturações tanto no nível administrativo, pela proliferação de contratos temporários - com duração de dois anos - e por subcontratação de profissionais terceirizados; como no nível operacional, devido à automação da linha de montagem, que intensificou a substituição da força de trabalho e, consequentemente, redução no número de trabalhadores.

Em relação à divergência entre sindicato metalúrgico e demandas da subsidiária, surge nos relatos o termo descaso que se justifica pela presença de sindicato compartilhado ou reconduzido de outra indústria tradicional na região. Essa característica do sindicato foi 
mencionada repetidamente e reforça o argumento da fragmentação sindical no Brasil, alertado por Dal Rosso (2013), que se materializa no estudo com interlocução deficiente de representantes alheios aos problemas específicos da montadora.

Outro aspecto ligado à origem na siderurgia foi a diferença das categorias profissionais dos trabalhadores como obstáculo para as negociações, visto que isso tem influenciado a condução dos acordos coletivos. O distanciamento entre trabalhadores e o sindicato tem aberto espaços para o discurso persuasivo da organização aludindo à situação de crise e à iminência de novas demissões. Conversas internas foram reproduzidas para ilustrar tal evento e remete à pesquisa de Anner (2014), no tocante ao uso dos mesmos pretextos.

Em termos de cooptação, foi possível adaptar o esquema triangular em que o sindicato apresenta vínculos com governos e empresas. Os respondentes tacham o sindicato como corrupto e partidário justamente por enxergá-lo como um ente eminentemente político. Nesse sentido, a pesquisa de campo levanta elementos explorados na temática da guerra fiscal referentes à desmobilização política local. Os sindicatos tangenciam esses debates porque, juntamente com privilégios e/ou benefícios fiscais, condições de trabalho mais flexíveis confrontam a representação do trabalhador.

No caso investigado, a cooptação também ocorre na aresta empresa-sindicato, indicando o estranhamento de pesquisadores como Soares (2013), ao tratar de partes originalmente opostas. O ceticismo aparece nos relatos em termos como conchavo ou favorecimento. Além disso, a descrição de tratativas nos acordos coletivos que sugere uma aproximação nociva para os resultados das negociações. Ainda que no campo especulativo, chamou a atenção, na fase de entrevistas, a similaridade de opiniões sobre a postura do sindicato.

Novamente, é importante ressaltar a profusão de estudos realizados sobre o assunto na última década, o que significa uma preocupação não apenas no Brasil, mas também em outros países emergentes (GASTROW, 2012). Desta forma, o artigo sinaliza os arranjos complexos da rede de produção global automotiva que conjumina sistemas econômicos, políticos e discursivos (LEVY, 2008). Em caráter regional, desdobramentos específicos têm implicado diferentes nuances da flexibilidade nas condições de trabalho.

Dos temas apontados na literatura, os resultados da pesquisa no sul fluminense reforçam dois aspectos e amplia um terceiro. Quando comparados com outros estudos empíricos, ressurgem temas como a fragmentação institucional - subdivisão do sindicato regional metalúrgico -, e a questão do regionalismo que caracteriza o market seeking 
automotivo nas últimas décadas. Ambos os achados encontram semelhança em pesquisas nos países emergentes, como leste europeu (DRAHOKOUPIL; MYANT; DOMONKOS, 2015) e Coreia do Sul (AELIM, 2011); apenas para citar alguns casos.

Entretanto, idiossincrasias nas respostas dos trabalhadores quanto à cooptação tanto em relação à empresa como em sentido político genérico, possibilitaram ampliar discussões sobre a atuação sindical pela lente das teorias de negócios internacionais e de empresas multinacionais. Esse diálogo ficou representado pela adaptação dos trabalhos de Grosse e Behrman (1992) e Stopford (2005), ilustrado no esquema triangular da Figura 2. Onde originalmente aparece comunidade, o sindicato foi situado como componente relevante de um arranjo local com interfaces com escopo internacional das operações na indústria automotiva.

Historicamente, os sindicatos tem sido parte importante justamente porque representam a interlocução do trabalhador. Entretanto, pesquisas recentes descortinam o progressivo desequilíbrio na balança capital-trabalho que, dentre diversos mecanismos, é viabilizado pela migração de subsidiárias para novas regiões produtivas, como o sul fluminense. Tal assimetria pode instigar pesquisas na aresta empresa-governo; com vistas em investigar como políticas públicas na indústria podem estar marginalizando a atuação do sindicato.

\section{REFERÊNCIAS}

ABDI. O Núcleo Tecnológico da Indústria Brasileira. In: DE NEGRI, João Alberto; LEMOS, Mauro Borges (Org.). Brasília: IPEA-FINEP-ABDI, 2011.

ADAMS, Z.; DEAKIN, S. Institutional solutions to precariousness and inequality in labour markets. British Journal of Industrial Relations, v. 52, n. 4, p. 779-809, 2014.

AELIM, Y. Building collective identity: trade union representation of precarious workers in the South Korean auto companies. Labour, Capital \& Society, v. 44, n. 1, p. 154-178, 2011. ALVAREZ, R. R. Setor automotivo no Rio De Janeiro: uma análise da inserção dos fabricantes locais de autopeças na cadeia automotiva. Tese Doutorado Universidade Federal do Rio de Janeiro (UFRJ), Coordenação dos Programas de Pós Graduação em Engenharia (COPPE), Rio de Janeiro, 2004.

ANAF, J.; NEWMAN, L.; BAUM, F.; ZIERSCH, A.; JOLLEY, G. Policy environments and job loss: Lived experience of retrenched Australian automotive workers. Critical Social Policy, v. 33, n. 2, p. 325-347, 2012. 
ANNER, M. et al. Determinantes industriais da solidariedade transnacional: política intersindical global em três setores. Estudos Avançados., v. 28, n. 81, p. 229-250, 2014. ARAÚJO, S. M. A indústria automobilística, o trabalho e o capital migrante em novas regiões produtivas brasileiras. Revista Paranaense de Desenvolvimento, n. 123, julho/dezembro, 2012.

ASSOCIAÇÃO NACIONAL DOS FABRICANTES DE VEÍCULOS AUTOMOTORES ANFAVEA. Anuário da indústria automobilística brasileira. São Paulo: ANFAVEA, 2016.

AUGUSTO JUNIOR, F.; BELZUNCES, R.; CAMARGO, Z. M.; SOARES, W. B. Desenvolvimento e estrutura da indústria automotiva no Brasil. 2015. Nota técnica, DIEESE n. $152,2015$.

BARDIN, L. Análise de conteúdo. São Paulo: Edições 70, 2011.

BARROS, D. C.; PEDRO, L. S. As mudanças estruturais do setor automotivo, os impactos da crise e as perspectivas para o Brasil. BNDES Setorial, n. 34. Rio de Janeiro: BNDES, 2011.

BENGTSSON, E. Do unions redistribute income from capital to labour? Union density and wage shares since 1960. Industrial Relations Journal, v. 45, n. 5, p.3 89-408, 2014.

BERG, B. L. Qualitative research methods for the social sciences. San Francisco: Califormia University Press, 2009.

BOLSMANN, C. Contesting labor internationalism: The "old" trapped in the "new" in Volkswagen's South African plant. Labor Studies Journal, v. 35, n. 4, p. 520-539, 2010. BRASIL. Ministério do Trabalho (MTE). Relação Anual de Informações Sociais (RAIS). Disponível em: <http://portal.met.gov/rais> . Acesso em: 7 fev. 2014.

BRIDI, M. A. Ação sindical, acordos coletivos e condições de trabalho na moderna indústria automobilística do Paraná. In: Silvia Maria de Araújo (Org.). Trabalho e capital em trânsito: a indústria automobilística no Brasil. Curitiba: Editora UFPR, 2007. p. 165-191. CHUNG, C. The transfer of HRM practices to India subsidiaries in a South Korean MNE in the auto industry. In: Anthony P. D’Costa (Eds.), After-development dynamics: South Korea's contemporary engagements with Asia. Oxford : Oxford University Press, 2015. p.119.

CANTIN, É. Globalization and precarious forms of production and employment: challenges for workers and unions. Industrial Relations, v. 68, n. 1, p. 178-181, 2013.

CASTRO, T. G. de; ABS, D; SARRIERA, J. C. Análise de conteúdo em pesquisas de Psicologia. Psicol. Cienc., v. 31, n. 4, p. 814-825, 2011. 
COELHO, A. L. C. O quinto ciclo da Guerra Fiscal e a nova indústria automobilística brasileira. Revista de Desenvolvimento Econômico, Salvador, Ano XIV, n. 26, p. 51-65, 2012 .

DAL ROSSO, S. Fragmentação sindical. Educ. rev., n. 48, p.3 9-52, 2013.

DELGADO, I. G. Política industrial para os setores farmacêutico, automotivo e têxtil na

China, Índia e Brasil. Texto para Discussão, IPEA n. 2087, 2015.

DESLANDES, S. F.; CRUZ NETO, O./ MINAYO, M. C. de S. (Orgs.). Pesquisa social: teoria, método e criatividade. Petrópolis : Vozes, 1994.

DICKEN, P. Global shift: mapping the changing contours of the world economy. London: Sage Publishers, 2011.

DRAHOKOUPIL, J.; MYANT, M.; DOMONKOS, S. The politics of flexibility:

Employment practices in automotive multinationals in central and eastern Europe. European Journal of Industrial Relations, v. 21, n. 3, p. 223-240, 2015.

DUARTE, R. Pesquisa qualitativa: reflexões sobre o trabalho de campo. Caderno de Pesquisa, n. 115. São Paulo: Fundação Carlos Chagas, maio de 2002.

FLEIG, D. G. et al . Reestruturação produtiva e subjetividade: análise interpretativa do significado do desemprego. Organ. Soc., v. 12, n. 33, p. 71-91, 2005.

FRANCISCO, E. M V. A comissão enxuta: ação política no “consórcio modular”. In: RAMALHO, J. R. R.; SANTANA, M. A. (Org.). Trabalho e desenvolvimento regional. Rio de Janeiro: Mauad, 2006. p. 199-226.

FRANCO, M. L. P. B. Análise de conteúdo. Brasília: Líber Livro, 2005.

FRANCO, A. Em tempos globais, um "novo" local: a Ford na Bahia. Cad. CRH, v. 22, n. 56, p. 359-380. 2009

GARCIA, S. R. Agentes globais e esfera local: o pólo automobilístico de Gravataí. Sociologias, Porto Alegre, n. 23, p. 238-266, 2010.

GASTROW, M. A review of trends in the global automotive manufacturing industry and implications for developing countries. African Journal of Business Management, v. 6, n. 19, p. 5895- 5905, 2012.

GOMES, R. Análise e interpretação de dados de pesquisa qualitativa. In: DESLANDES, S. F.; CRUZ NETO, O./ MINAYO, M. C. de S. (Orgs.). Pesquisa social: teoria, método e criatividade. Petrópolis: Vozes, 2009. p. 79-108.

GROSSE, R.; BEHRMAN, J. Theory in internacional business. Transcendental corporations, n. 1, p. 93-126, 1992. 
INSTITUCIONAL GRUPO AUTOMOTIVO, 2016. Disponível em:

<www.psapeugeotcitroen.com.br>. Acesso em: 7 dez. 2015.

KÖHLER, H; CALLEJA JIMÉNEZ, J. P. "They don't represent us!" Opportunities for a social movement unionism strategy in Spain. Industrial Relations, v. 70, n. 2, p. 240-261, 2015 .

KUBONIWA, M. Present and future problems of developments of the Russian auto-industry. RRC Working Paper Series, n. 15, p. 1-12, 2009.

LAWLER, J.J. et al. Going abroad: HR policies, national IR systems, and union activity in foreign subsidiaries of U.S. multinationals. Industrial \& Labor Relations Review, v. 66, n. 5, p. 1149-1171, 2013.

LÉVESQUE, C.; BENSUSÁN, G.; MURRAY, G.; NOVICK M.; CARRILLO, J.; GURRERA, S. Labour relations policies in multinational companies: A three-country study of power dynamics. Journal of Industrial Relations, v. 57, n. 2, p. 187-209, 2015. LEVY, D. Political Contestation in Global Production Networks. Academy of Management, Special Issue v. 33, n. 4, p. 1-47, 2008.

LIMA, R. J. C. Empresariado local, indústria automobilística e a construção de Porto Real (RJ). In: RAMALHO, J. R. R.; SANTANA, M. A. (Org.). Trabalho e desenvolvimento regional. Rio de Janeiro: Mauad, 2006. p. 43-70.

LIMA, U. M. A. Dinâmica e o Funcionamento da Cadeia Global de Valor da Indústria Automobilística na Economia Mundial. Texto para Discussão, IPEA n. 2065, 2015. LIMA, U. M. A. Brasil e a cadeia automobilística: uma avaliação das políticas públicas para maior produtividade e integração internacional entre os anos 1990 e 2014 . Texto para Discussão, IPEA n. 2167, 2016.

LÜTHJE, B. Labour relations, production regimes and labour conflicts in the chinese automotive industry. International Labour Review, v. 153, n. 4, p. 535-560, 2014. McCRACKEN, G. The long interview. Newbury Park: Sage Publications, 1988. MAGNANI, E.; PRENTICE, D. Did lower unionization in the United States results in more flexible industries? Industrial \& Labor Relations Review, v. 63, n. 4, p. 662-680, 2010. NASCIMENTO, R. P.; SEGRE, L. M. O modelo de relações salariais: uma análise de empresas automobilísticas no Brasil. Cad. EBAPE.BR, v. 6, n. 2, p. 1-16, 2008.

NEVES, M. A; CARVALHO NETO, A. Fatores locacionais, processo e relações de trabalho nos novos espaços de produção da indústria automotiva. In: ARAÚJO, S. M. (Org.). Trabalho e capital em trânsito: a indústria automobilística no Brasil. Curitiba: Editora UFPR, 2007. p.2 5-49. 
PAULA, E. K. de. Polo Automotivo Sul Fluminense: novos rumos para o desenvolvimento econômico da região. Dissertação de Mestrado em Políticas Públicas, Estratégia e Desenvolvimento - Instituto de Economia, Universidade Federal do Rio de Janeiro, Rio de Janeiro, 2015.

PULIGNANO, V.; LUCIO, M. M.; WALKER, S. Globalization, restructuring and unions: transnational co-ordination and varieties of labour engagement. Industrial Relations, v. 68, n. 2, p. 261-289, 2013.

PULIGNANO, V.; GERVASI, L. O.; FRANCESCHI F. de. Union responses to precarious workers: Italy and Spain compared. European Journal of Industrial Relations, v. 22, n.1, p. 39-55, 2016.

RAMALHO, J. R.; SANTANA, M. A. Um perfil dos trabalhadores do consórcio modular. In: RAMALHO, J. R. R.; SANTANA, M. A. (Org.). Trabalho e desenvolvimento regional. Rio de Janeiro: Mauad, 2006. p. 91-110.

RAMALHO, J. R.; RODRIGUES, I. J.; CONCEIÇÃO, J. J. Reestruturação industrial, sindicato e território - alternativas políticas em momentos de crise na região do $\mathrm{ABC}$ em São Paulo - Brasil. Revista Crítica de Ciências Sociais, n. 85, p. 147-167, 2009.

RAMALHO, J. R.; RODRIGUES, I. J. Sindicato, crise econômica e estratégias regionais novas dimensões da participação política no ABC Paulista. Cad. CRH, v. 23, n. 59, p. 339$351,2010$.

RAMALHO, J. R.; RODRIGUES, I. J. Sindicato, desenvolvimento e trabalho: crise econômica e ação política no ABC. Cad. CRH, v. 26, n. 68, p. 217-231, 2013. ROESCH, S.; FERNANDES, F. Como escrever casos para o ensino de administração. São Paulo: Atlas, 2007.

ROESCH, S. M. A. Projetos de estágio e de pesquisa em administração: guia para estágios, trabalhos de conclusão, dissertações e estudos de caso. São Paulo: Atlas, 2009. SILVA, T. C. Novas Centrais Sindicais: desafios e limites na contemporaneidade. Primeiros Estudos, n. 2, p. 119-143, 2012.

SIMMONS, L; CONLO, S; MUKHOPADHYAY, S; YANG, J. A Computer aided content analysis of online reviews. Journal of Computer Information Systems, v. 52, n.1, p. 43-55, 2011.

SOARES, J. L. As centrais sindicais e o fenômeno do transformismo no governo Lula. Soc. Estado., v. 28, n. 3, p. 541-564, 2013.

STAKE, R. E. Qualitative research: studying how things work. New York: Guilford Press, 2010 . 
STOPFORD, J. Revisiting rival states. In: GROSSE, R. (Ed.). Government relations in the 21st century. Cambridge University Press, 2005.

TANIGUTI, G. T. Práticas sindicais na Toyota do Brasil: os casos de São Bernardo do Campo (SP) e Indaiatuba (SP). Plural, v. 16, n. 2, p. 33-64, 2009.

TANIGUTI, G. T. Sindicatos e relações de trabalho na Toyota do Brasil: São Bernardo do Campo e Indaiatuba em uma perspectiva comparada. Dissertação de Mestrado em

Sociologia) - Faculdade de Filosofia, Letras e Ciências Humanas, Universidade de São Paulo, São Paulo, 2010.

VERGARA, S. C. Métodos de pesquisa em administração. São Paulo, Atlas, 2005.

VERGARA, S. C. Métodos de coleta de dados em campo. São Paulo. Editora Atlas, 2009. ZHU, J. S. Chinese multinational corporations' responses to host country trade unions: An eclectic approach. Journal of Industrial Relations, v. 57, n. 2, p. 232-249, 2015.

WAD, P. Global Challenges and local responses: trade unions in the Korean and Malaysian auto industries. Copenhagen Discussion Papers, v. 3, 2005.

WADDINGTON, J. Trade union membership retention in Europe: the challenge of difficult times. European Journal of Industrial Relations, v. 21, n. 3, p. 205-221, 2015. 